\title{
Optomechanical Design of a Compact Imaging Spectrometer for a Microsatellite STSAT3
}

\author{
Jun Ho Lee* and Chi Weon Lee \\ Department of Optical Engineering, Kongju National University, Kongju 314-701, Korea \\ Yong Min Kim \\ Mirea Technology, Daejeon 302-150, Korea \\ Jae Wook Kim \\ Department of Mechanical Engineering, KAIST, Daejeon 305-701, Korea
}

(Received April 1, 2009 : revised April 22, 2009 : accepted April 22, 2009)

\begin{abstract}
A compact imaging spectrometer (COMIS) is currently under development for use in the STSAT3 microsatellite. COMIS images the Earth's surface and atmosphere with ground sampling distances of $\sim 30 \mathrm{~m}$ in the $18 \sim 62$ spectral bands $(4.0 \sim 1.05 \mu \mathrm{m})$ for the nadir looking at an altitude of $700 \mathrm{~km}$. COMIS has an imaging telescope and an imaging spectrometer box into which three electronics PCBs are embedded. These are designed into a single assembly with dimensions of $35(\mathrm{~L}) \times 20(\mathrm{~W})$ $\times 12(\mathrm{H}) \mathrm{cm}^{3}$ and a mass of $4.3 \mathrm{~kg}$. Optomechanical design efforts are focused on manufacturing ease, alignment, assembly, testing and improved robustness in space environments. Finite element analysis demonstrates that COMIS will survive in launch and space environments and perform the system modulation transfer function (MTF) in excess of 0.29 at the Nyquist frequency of the CCD detector (38.5 lines-per-mm).
\end{abstract}

Keywords: Imaging spectrometer, STSAT3, Space optics, Optomechanics

OCIS codes : (200.4880) Optomechanics; (220.4830) Optical systems design; (300.6190) Spectrometers; (350.6090) Space optics

\section{INTRODUCTION}

A compact imaging spectrometer (COMIS) is currently under development for use in the STSAT3 microsatellite [1]. COMIS images the Earth's surface and atmosphere with ground sampling distances of $\sim 30 \mathrm{~m}$ in the $18 \sim 62$ spectral bands $(4.0 \sim 1.05 \mu \mathrm{m})$ of the nadir at an altitude of $700 \mathrm{~km}$ (Fig. 1). A major scientific application of COMIS is environmental monitoring, a recent example being the in-land water quality monitoring of Paldang Lake, a body of water located near Seoul, South Korea [2].

COMIS is a conventional imaging spectrometer consisting of imaging and dispersion relay optics. The entrance pupil diameter of the optics is $65 \mathrm{~mm}$. The imaging telescope, which operates at an f-ratio of 4.6 , forms an image (of the Earth's surface or atmosphere) onto an intermediate image plane. The imaging spectrometer disperses light from the slit and reimages it onto a CCD. The optical axis of the entrance and exit beams are designed parallel to that of the imaging telescope. This eases alignment difficulties and makes the optics less sensitive to thermal contraction and expansion of the mechanical housing. All optical surfaces are spherical. Details of the optics design were presented in a previous publication [3]. Table 2 summaries the specification of COMIS.

COMIS, as implied by its name, is very compactly designed to survive in launch and space environments and to maintain optical performances on orbits. This paper presents the optomechanical design of COMIS as well as a demonstration of its validity through finite element analysis (FEA).

*Corresponding author: jhlsat@kongju.ac.kr 

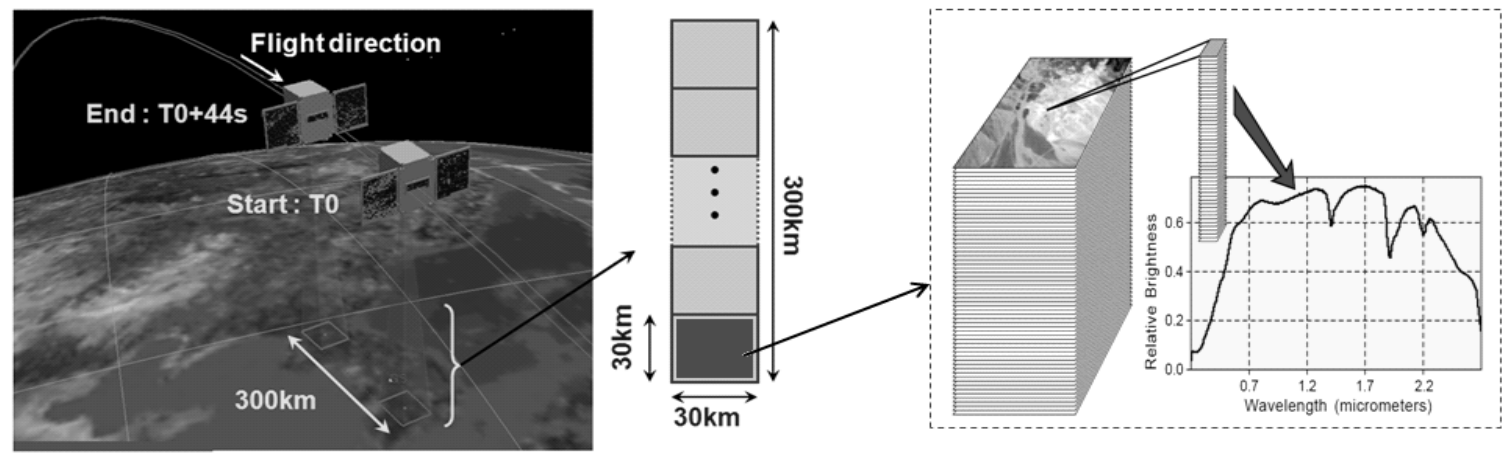

FIG. 1. The COMIS Strip imaging mode-one scene consists of a $30 \mathrm{~km}$ by $30 \mathrm{~km}$ image of Earth at 18 64 wavebands.

TABLE 1. COMIS specification.

\begin{tabular}{c|c}
\hline \hline Item & Specification \\
\hline Platform & STSAT3 \\
\hline Orbits & $\begin{array}{c}\text { Sun-synchronous orbits at an } \\
\text { altitude of } 700 \mathrm{~km}\end{array}$ \\
\hline GSD @ 700km & $<30 \mathrm{~m}$ \\
\hline Swath width & 1000 GSDs $(\sim 30 \mathrm{~km})$ \\
\hline Spectral bands & $450-1050 \mathrm{~nm}$ \\
\hline Spectral resolution & $2 \sim 15 \mathrm{~nm}$ \\
\hline No. of spectral bands & $18 \sim 64$ \\
\hline Mass & $<5 \mathrm{~kg}(4.3 \mathrm{~kg})$ \\
\hline CCD & E2V CCD47-20 \\
\hline Imaging Area & $13.3 \mathrm{~mm} \times 13.3 \mathrm{~mm}$ \\
\hline Digitization & $12 \mathrm{bits}$ \\
\hline EPD & $65 \mathrm{~mm}$ \\
\hline Volume & $35 \mathrm{~cm} \times 20 \mathrm{~cm} \times 12 \mathrm{~cm}$ \\
\hline
\end{tabular}

\section{OPTOMECHANICAL DESIGN}

\section{Overall description}

COMIS is an integrated structure comprised of an imaging telescope and a box-like housing structure (simply a housing box) (Fig. 2). Dispersion relay optics with supports (mounts), a focal plane assembly (FPA), and three PCBs are mounted onto the housing. Fig. 3 shows the optical and mechanical layouts of COMIS. COMIS is very compact, measuring $35(\mathrm{~L}) \times 20(\mathrm{~W}) \times 12(\mathrm{H}) \mathrm{cm}^{3}$ and weighing only $4.3 \mathrm{~kg}$. Table 2 lists the mass allocation down to the sub-components. These include 1) optical components such as lenses, mirrors and prisms, 2) housing and mounts, 3) three PCBs and 4) accessories such as bolts, nuts and a harness.

A previous study budgeted modulation transfer function (MTF) degradation down to the degradation of major factors. These were the design (diffraction, aberration, obstruction), manufacturing/assembly errors, instability in space, detector integration, satellite drift motion and

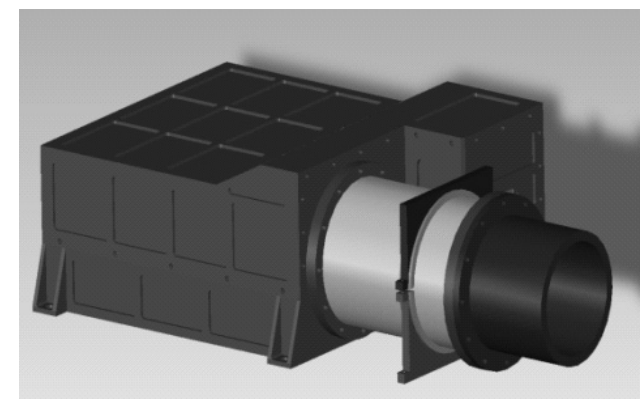

FIG. 2. COMIS 3D Model.

TABLE 2. Mass allocation of COMIS.

\begin{tabular}{c|c}
\hline \hline Item & Mass $(\mathrm{kg})$ \\
\hline Optical Components & 1.1 \\
\hline Housing \& mounts & 2.3 \\
\hline PCBs & 0.5 \\
\hline Accessory & 0.4 \\
\hline Total & 4.3 \\
\hline
\end{tabular}

satellite jitter motion [3]. Table 3 tabulates the detailed system MTF allocations. It is important to note that the degradation of 'manufacturing/alignment errors' includes not only degradation occurring on the surface of the Earth [4], but also any misalignment that occurs during the launch. The table also shows that instability in space is the most significant MTF degradation factor in addition to detector integration, which is inevitable. Therefore, mechanical design efforts are focused on minimizing the effects of instability and ensuring mechanical integrity and compactness.

Instabilities in space are induced mainly by temperature changes as STSAT-3 orbits the Earth. To minimize thermo-optical effects, a single-material athermalization approach is adopted for the imaging telescope while a quick-thermal equilibrium approach is used for the housing box. 


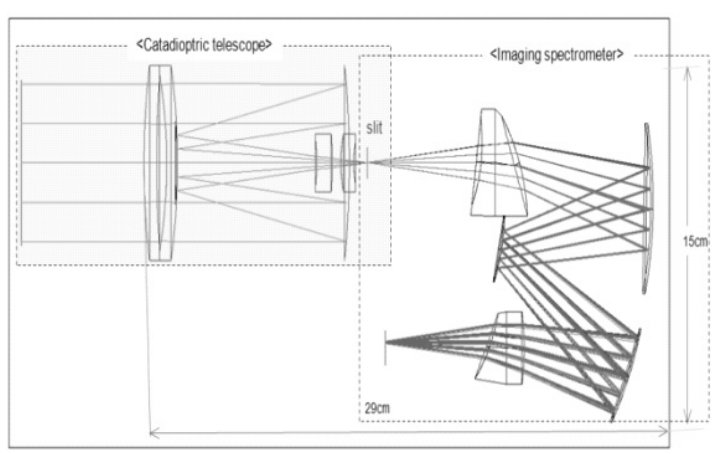

(a) Optical layout

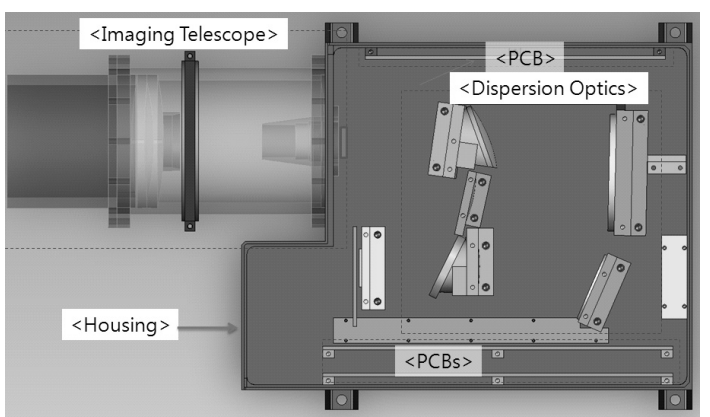

(b) Mechanical layout

FIG. 3. The COMIS Strip imaging mode-one scene consists of a $30 \mathrm{~km}$ by $30 \mathrm{~km}$ image of Earth at $18^{\sim} 64$ wavebands.

TABLE 3. System MTF allocation of COMIS.

\begin{tabular}{l|l|c|l}
\hline \hline \multicolumn{2}{l|}{ Item } & MTF @ 38.5 lpm & Note \\
\hline \multicolumn{2}{l}{ Design MTF } & 0.63 & Diffraction + Aberration + Obstruction \\
\hline \multirow{2}{*}{$\begin{array}{l}\text { Manufacturing } \\
\text { Alignment }\end{array}$} & Imaging Telescope & 0.98 & \multirow{2}{*}{ Manufacturing + Assembly/Alignment + Testing } \\
\cline { 2 - 3 } $\begin{array}{l}\text { Instability in } \\
\text { space }\end{array}$ & Imaging Spectrometer & 0.98 & \multirow{2}{*}{ Gravity Release + Thermal Expansion/Contraction } \\
\cline { 2 - 4 } & Imaging Spectrometer & 0.90 & 1 pixel $(38.5$ lpm $)$ \\
\hline Detector Integration & 0.64 & 0.1 pixel movement over a pixel CCD integration time \\
\hline Linear motion & 0.98 & 0.014 pixel random vibration over CCD integration \\
\hline Jitter & 0.99 & \\
\hline Resultant System MTF & 0.29 & \\
\hline
\end{tabular}

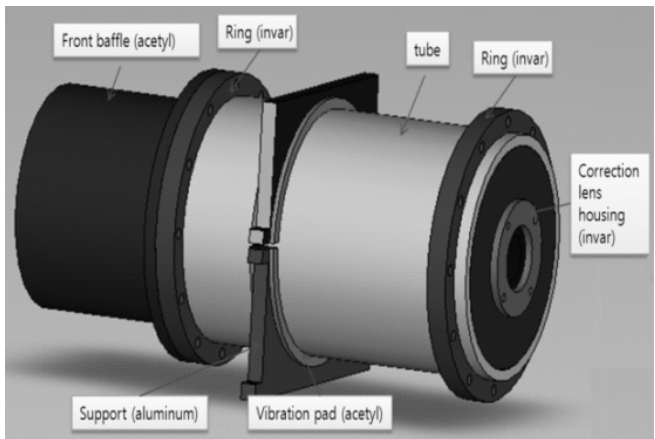

(a) 3D model

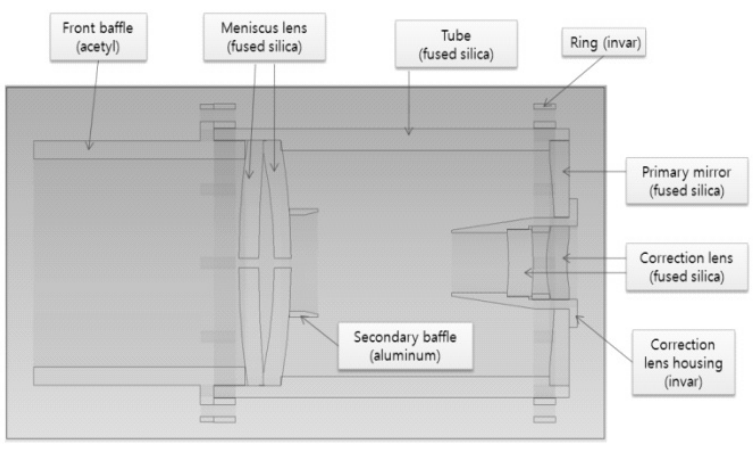

(b) Cross-sectional view

FIG. 4. Labeled 3D model and cross-sectional view of the imaging telescope.

\section{Imaging Telescope Design}

The imaging telescope essentially consists of a single material, fused silica. The thermal expansion coefficient of fused silica is nearly zero $\left(0.5 \times 10^{-6} /{ }^{\circ} \mathrm{C}\right)$ compared to that of ordinary optical glass such as BK7 $\left(7.1 \times 10^{-6} /{ }^{\circ} \mathrm{C}\right)$ $[5,6]$. In that sense, this design approach can also be termed zero-expansion athermalization. The most important dimension for nearly all telescopes is the distance between the primary and secondary mirror. This distance is conventionally kept unchanged by the use of invar rods [7] or composite materials [8]. These options were excluded to limit the mass and simplify the manufacturing process. A tube made of fused silica is applied in this design to meet the single material approach. Both ends of the tube are surrounded by invar rings which are assembled into the front baffle and the housing box, respectively. As the thermal expansion coefficient of invar is also virtually zero $\left(1 \times 10^{-6} /{ }^{\circ} \mathrm{C}\right)$, the tube does not experience any significant thermal stresses due to the thermal cycling in orbit. Fig. 4 shows a 3D model and a cross-sectional view of the imaging telescope, including the names of the parts and the materials used. Table 4 lists the opto-mechanical properties of the materials. 
TABLE 4. Opto-mechanical properties of the materials used $[5,6]$.

\begin{tabular}{c|c|c|c|c|c}
\hline \hline \multirow{2}{*}{ Material } & $\begin{array}{c}\text { Thermal expansion } \\
\text { coefficient }\end{array}$ & Young's modulus & Density & Specific heat & $\begin{array}{c}\text { Thermal } \\
\text { conductivity }\end{array}$ \\
\cline { 2 - 6 } & $1 \times 10^{-6} /{ }^{\circ} \mathrm{C}$ & $\mathrm{Gpa}$ & $\mathrm{kg} / \mathrm{m}^{3}$ & $\mathrm{~J} / \mathrm{Kg}^{\circ} \mathrm{C}$ & $\mathrm{W} / \mathrm{m}^{\circ} \mathrm{C}$ \\
\hline Fused silica & 0.5 & 73 & 2190 & 750 & 1.4 \\
\hline Aluminum alloy & 23 & 69 & 2770 & 875 & 171 \\
\hline Invar & 1.0 & 141 & 8050 & 515 & 10.4 \\
\hline PCB & 21 & 22 & 1850 & 1000 & 10 \\
\hline
\end{tabular}

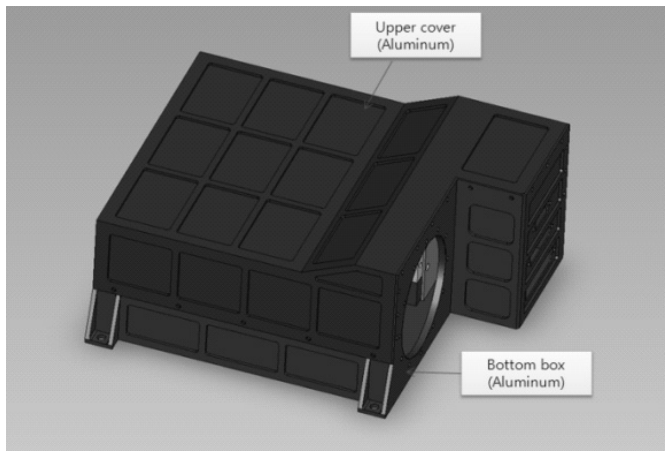

(a) $3 \mathrm{D}$ model

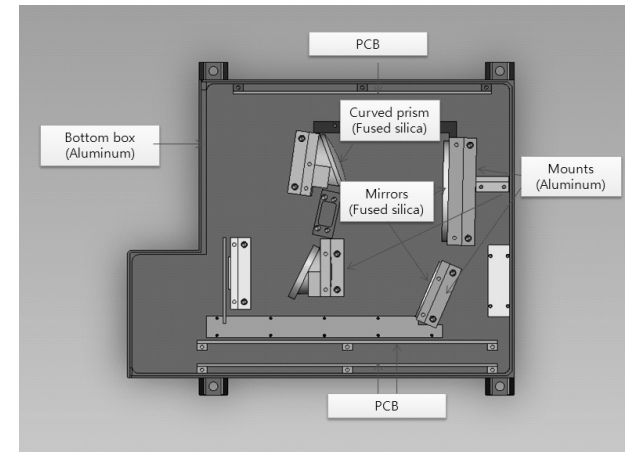

(b) Inside view

FIG. 5. Labeled 3D model and cross-sectional view of the housing box.

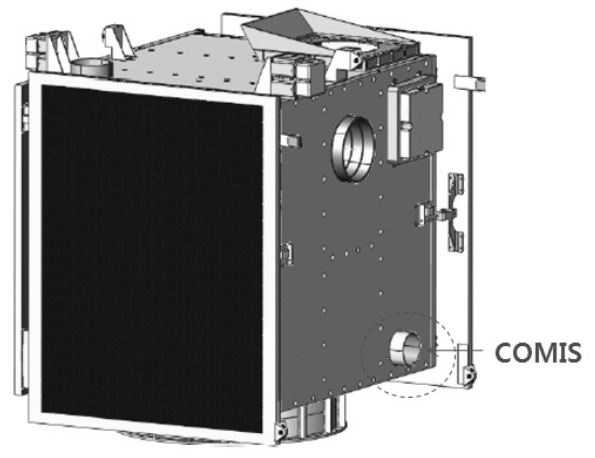

(a) Stowed configuration

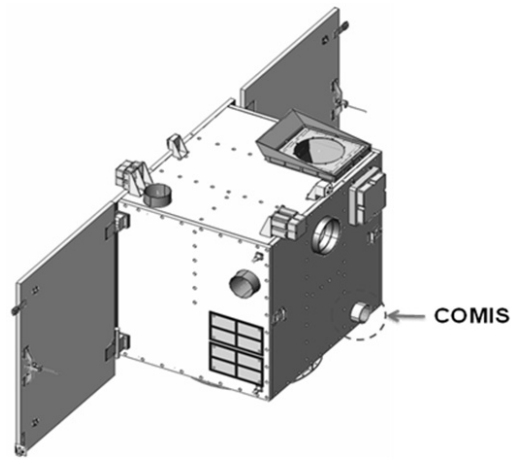

(b) Exploded configuration

FIG. 6. STSAT3 models indicating COMIS with dotted circles.

\section{Housing Box Design}

Dispersion optics was designed to make the optical axis of the entrance and exit beams parallel to that of the imaging telescope (Fig. 3) so that the thermal contraction/elongation of the object (slit) distance is selfcompensated by that of the image distance. Therefore, the housing box and supports are all made of aluminum due to its excellent manufacturability and high thermal conductivity. High thermal conductivity is very desirable in this approach so that the box will quickly reach thermal-equilibrium i.e., a uniform temperature throughout the box. Fig. 5 shows a 3D model and inside view of the housing box, including the names of the parts and the materials used.

\section{COMIS on the STSAT3 platform}

STSAT-3 is a microsatellite, weighing approximately $150 \mathrm{~kg}$ including the two payloads of MIRIS for IR imaging of the Galaxy (at 1-2 $\mu \mathrm{m}$ wavelengths) [9] and COMIS for hyper-spectral imaging of the Earth's surface (in the visible and near-IR bands at 0.4 1.05 $\mu \mathrm{m}$ wavelengths). STSAT-3 is an H-framed composite structure and measures approximately $71 \mathrm{~cm} \times 87 \mathrm{~cm} \times 107 \mathrm{~cm}$ in a stowed configuration [10]. The COMIS hyper-spectral imager is located on the bottom panel of the bus platform, as shown in Fig. 6. COMIS is indicated by the dotted circles in the figure. Fig. 7 shows the internal view of STSAT-3 and the mechanical interfaces of COMIS to STSAT-3. 


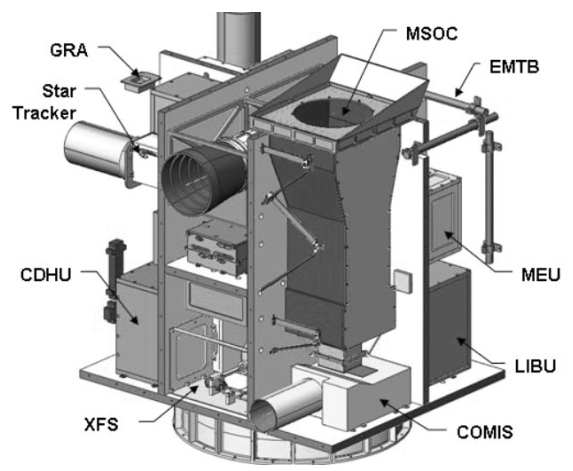

(a) Internal view of STSAT3; COMIS is located on the STSAT3 bottom panel

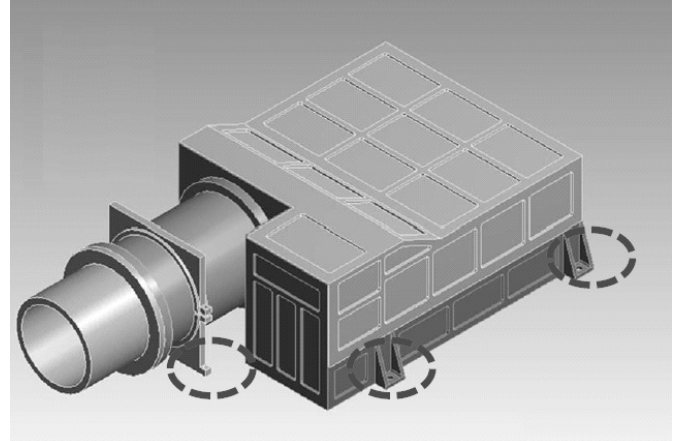

(b) COMIS is assembled onto the STSAT3 bottom panel by six M6 bolts

FIG. 7. Mechanical interfaces of COMIS to the STSAT3 platform.

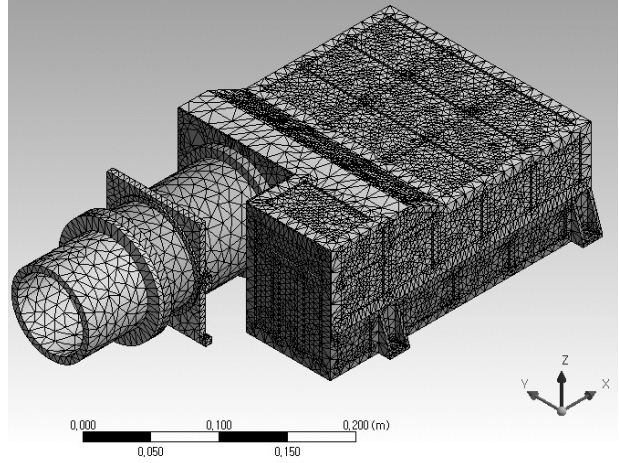

(a) FEA model with a cover plate

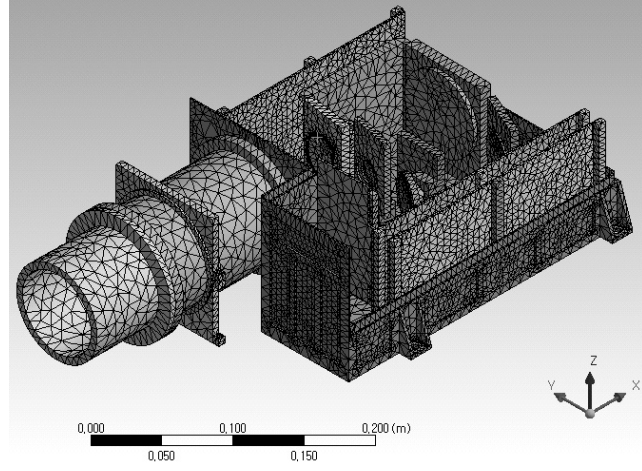

(b) FEA model without a cover plate

FIG. 8. COMIS FEA model for static and response analysis with 230814 nodes and 110675 elements.

The optical axis of COMIS is normal to the face panel so that it is pointed in the same direction as the antennas are oriented. As the antennas are pointed toward the ground station located in Daejeon, South Korea, COMIS will always be able to maintain line of sight over the Korean Peninsula when STSAT-3 is passing overhead.

\section{ANALYSIS}

\section{Analysis Model}

A FEA model of COMIS was modeled in a commercial FEA program [11] with 230814 nodes and 110675 elements for static and response analysis. The material properties in Table 4 were used. Given that a launcher for STSAT-3 was not selected at the time of this writing, the mechanical requirements for COMIS are from ARIANE-5, which is one of the most stringent launchers [12].

\section{Static Load Analysis}

COMIS will experience quasi-static loads during a launch of $10 \mathrm{~g}$ (i.e., 10 times gravitational acceleration) for the axial and $4 \mathrm{~g}$ for the lateral directions. The axial and lateral directions are the $\mathrm{z}$-axis and the $\mathrm{x}$ - $/ \mathrm{y}$ - axis in Fig. 8. Fig. 9 shows the stresses and deformations of COMIS for a $1 \mathrm{~g}$ static load along the $\mathrm{x}, \mathrm{y}$ and $\mathrm{z}$ axes. Table 5 lists the maximum stress and margin of safety of COMIS for $1 \mathrm{~g}$ and launch quasi-static loads. COMIS is proven to be opto-mechanically safe during launches of quasi-static loads. The margin of safety follows the same equation applied to STSAT-3 platform:

$$
\begin{aligned}
& \text { Margin of saftey }=\frac{\text { Allowable Yield stress }}{\left(\mathrm{SF}_{\text {Yield }}\right)\left(\mathrm{SF}_{\text {stability }}\right)(\text { Design Stress })}-1 \\
& \text { where }\left(\mathrm{SF}_{\text {Yield }}\right) \text { is } 1.3 \text { and }\left(\mathrm{SF}_{\text {stability }}\right) \text { is } 1.2[12] .
\end{aligned}
$$

\section{Modal Analysis}

A satellite and its payloads can have resonances caused by their dynamic coupling to launching vibration. In order to avoid these resonances, satellites and payloads are requested to have natural frequencies larger than certain values given by the launch service provider $[12,13]$, which are $10 \mathrm{~Hz}$ in the lateral directions (x,y) and 25 $\mathrm{Hz}$ in the axial direction (z). Fig. 10 shows the first 10 resonance frequencies along with three resonance modes. 


\begin{tabular}{|c|c|c|c|}
\hline Force \& direction & Stress & Deformation (external) & Deformation (internal) \\
\hline $\begin{array}{c}1 \text { g along } \mathrm{z} \\
\text { (axial) }\end{array}$ & $\begin{array}{c}\text { 1g along } \mathrm{x} \\
\text { (lateral) }\end{array}$ \\
$\begin{array}{c}\text { 1g along } \mathrm{y} \\
\text { (lateral) }\end{array}$
\end{tabular}

FIG. 9. Stresses and deformations of COMIS for a $1 \mathrm{~g}$ static load along the $\mathrm{x}, \mathrm{y}$, and $\mathrm{z}$ axes.

TABLE 5. Maximum stress and margin of safety of COMIS for $1 \mathrm{~g}$ and quasi-static launch loads along the axial and lateral axes.

\begin{tabular}{c|c|c|c|c}
\hline \hline Direction & Maximum stress for $1 \mathrm{~g}$ & Max quasi-static load & Maximum stress (MPa) & Margin of Safety \\
\hline $\begin{array}{c}\mathrm{X} \text { axis } \\
\text { (lateral) }\end{array}$ & 0.681 & $4 \mathrm{~g}$ & 2.724 & 117 \\
\hline $\begin{array}{c}\text { Y axis } \\
\text { (lateral) }\end{array}$ & 0.419 & $4 \mathrm{~g}$ & 1.676 & 191 \\
\hline $\begin{array}{c}\mathrm{Z} \text { axis } \\
\text { (axial) }\end{array}$ & 0.824 & $10 \mathrm{~g}$ & 8.24 & 38 \\
\hline
\end{tabular}

\begin{tabular}{|c|c|}
\hline mode & Frequency[Hz] \\
\hline 1 & 60.213 \\
\hline 2 & 63.141 \\
\hline 3 & 77.014 \\
\hline 4 & 441.41 \\
\hline 5 & 447.77 \\
\hline 6 & 449.68 \\
\hline 7 & 502.64 \\
\hline 8 & 745.63 \\
\hline 9 & 752.81 \\
\hline 10 & 798.3 \\
\hline
\end{tabular}

FIG. 10. First ten natural frequencies of COMIS.

\section{Thermal Analysis}

STSAT-3 will orbit the earth on a sun-synchronous orbit at an altitude of $700 \mathrm{~km}$. STSAT-3 and COMIS on it will experience thermal cycles as it orbits (Fig. 11). Although time-varying temperature profiles of STSAT-3 and COMIS can be simulated extensively, their boundaries can be accurately predicted based on two extreme conditions: the worst hot condition, and the worst cold condition [14]. Fig. 11 shows the operational concept of STSAT-3 along with thermal models of STSAT-3 and COMIS. Thermal analysis of COMIS was carried out with thermal boundaries resulting from a thermal analysis of the platforms [15]. The results of the thermal analysis of COMIS are shown in Fig. 12.

The temperature of COMIS varies from $15^{\circ} \mathrm{C}$ to $23^{\circ} \mathrm{C}$ in the worst hot condition and from $-14.5^{\circ} \mathrm{C}$ to $-10^{\circ} \mathrm{C}$ in the worst cold condition. Those temperature ranges are all within the operational range of COMIS. It is also worth noting that maximum thermal expansion/contraction occurs at the front baffle and therefore has no effect on the optical performances. 


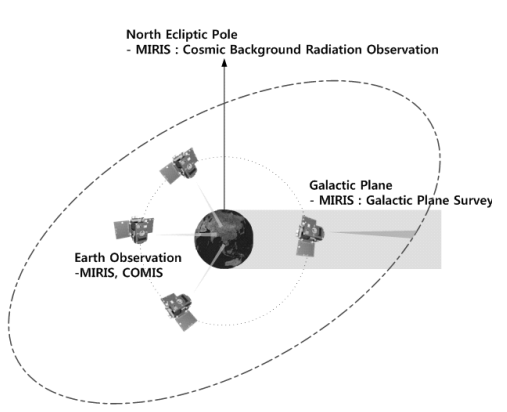

(a) Operational concept of STSAT-3

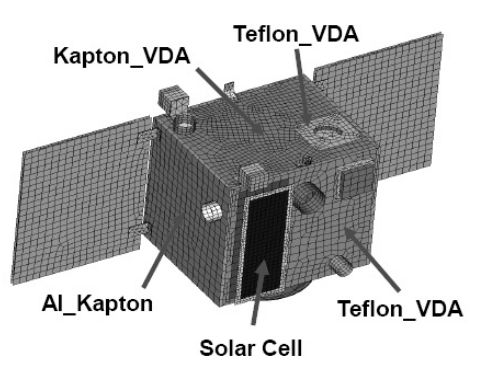

(b) STSAT-3 thermal model

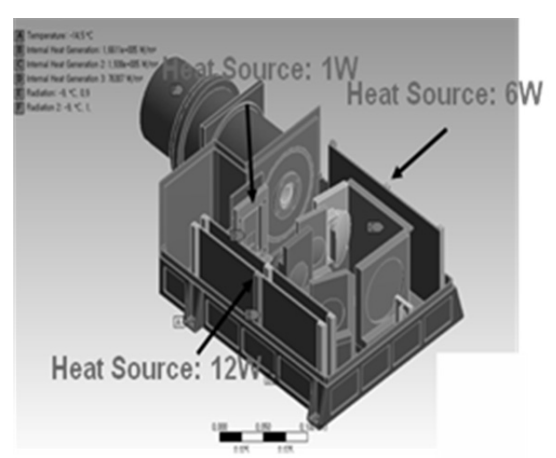

(c) COMIS thermal model

FIG. 11. Operational concept of STSAT-3 and thermal models of STSAT-3 and COMIS.

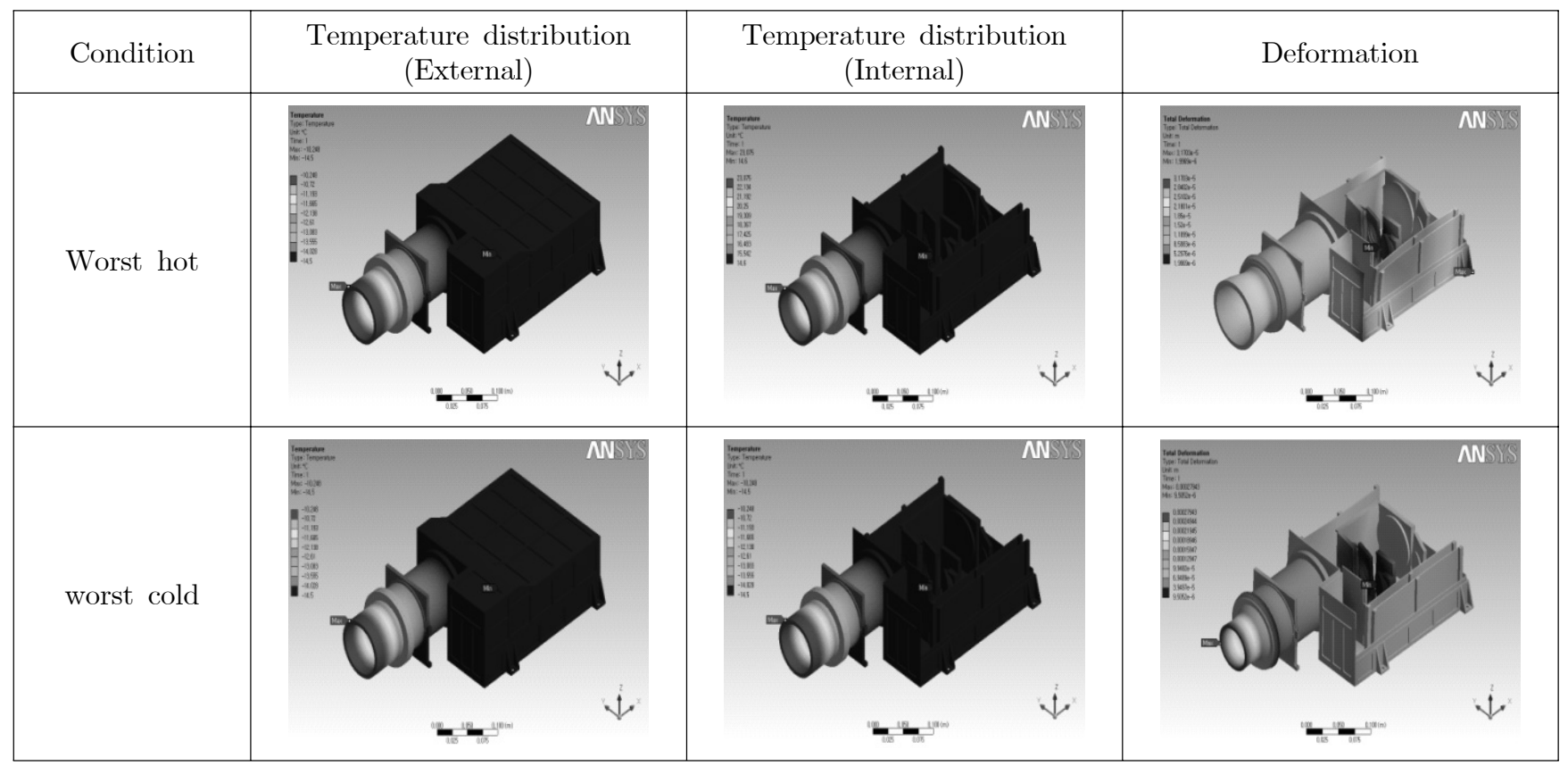

FIG. 12. Temperature distributions and deformations of COMIS for the worst hot and cold conditions.

\section{CONCLUSION}

A compact imaging spectrometer (COMIS) is currently under development for use in the STSAT3 microsatellite. COMIS was optically designed to achieve ground sampling distances of $\sim 30 \mathrm{~m}$ at the $18 \sim 62$ spectral bands $(4.0 \sim$ $1.05 \mu \mathrm{m})$ for the nadir looking at an altitude of $700 \mathrm{~km}$. Furthermore, manufacturing/alignment and stability errors were allocated to ensure a system modulation transfer function (MTF) in excess of 0.29 at the Nyquist frequency of the CCD detector (38.5 lines-per-mm). A compact opto-mechanical design realizes the allocation by adopting a single material approach for an imaging telescope and a quick-thermal-equilibrium approach for the spectrometer box. The design is demonstrated by finite element analysis to be stiff and stable enough to survive and operate during the launch and in orbit in space.

\section{ACKNOWLEDGMENT}

This work is funded by the Ministry of Education, Science and Technology, South Korea and is also supported by Korea Research Council of Fundamental Science \& Technology, South Korea.

\section{REFERENCES}

1. S. H. Lee, J. O. Park, S. W. Rhee, N. H. Myung, D. G. Lee, J. T. Lee, H. C. Bang, G. W. Moon, W. H. Choi, H. S. Kim, G. B. Chung, H. Han, J. H. Park, and J. H. Lee, "STSAT-3 satellite system," in Proc. the 2008 KSAS Spring Conference (Pyungchang, Korea, Apr. 2008), pp. 1093-1096.

2. J. H. Lee, C. W. Lee, K. I. Kang, T. S. Jang, H. S. Yang, W. Han, J. O. Park, and S. W. Rhee, "A compact 
imaging spectrometer (COMIS) for the microsatellite STSAT3," Proc. SPIE 6744, 67551C1-8 (2007).

3. J. H. Lee, T. S. Jang, H.-S. Yang, and S.-W. Rhee, "Optical design of a compact imaging spectrometer for STSAT3,” J. Opt. Soc. Korea 12, 262-268 (2008).

4. J. H. Lee, Y. M. Kim, J. S. Kim, and Y.-E. Yoo, "Bare wafer inspection using a knife-edge test,” J. Opt. Soc. Korea 11, 173-176 (2007).

5. A. Ahmad, Optomechanical Engineering Handbook (CRC Press LLC, Florida, USA, 1999), Chapter 3.

6. P. Yoder, Opto-mechanical Systems Design (Marcel Dekker, Inc., New York, USA, 1992), Chapter 3.

7. H.-G. Grothues, F. Lehmann, and H. Michaelis, "A compact very high resolution camera (VHRC) for earth and planetary exploration using a large array (7k x 8k) CCD," Acta Astronautica 45, 577-584 (1999).

8. B. Capdepuy, F. Leleu, F. Boursereau, P. Parrot, B. Bailly, J. B. Riti, and J. L. Cornu, "Space optical payloads, new application area for high temperature composites,"
Acata Astronautica 41, 825-831 (1997).

9. I.-S. Yuk, H. Jin, S. Lee, Y. S. Park, D. H. Lee, U. W. Nam, J. H. Park, W. Y. Han, and J. W. Lee, "Preliminary optical design of MIRIS, main payload of STSAT-3," Publications of the Korean Astronomical Society 22, 201-209 (2007).

10. H.-K. Cho, J.-K. Seo, N.-H. Myung, "Modal analysis for the development of composite structure of STSAT-3," Publication of Korea Society of Aero and Space 36, 12011206 (2008).

11. www.ansys.com

12. D. Mugnier, ASAP 5 Users Manual (Arianespace, France, 2000).

13. P. R. K. Chetty, Satellite Technology and Its Applications (Mcgraw-Hill, USA, 1991).

14. D. G. Gilmore, Satellite Thermal Control Handbook (Aerospace Corporation Press, USA, 1994).

15. J.-K. Seo, "STSAT-3 preliminary design review: spacecraft bus," STSAT-3 PDR meeting (2008). 